\title{
Suitability of a CMV/EGFP cassette to monitor stable expression from human artificial chromosomes but not transient transfer in the cells forming viable clones
}

\author{
A. Laner, ${ }^{a, b}$ T. Schwarz, ${ }^{a}$ S. Christan ${ }^{a, d}$ and D. Schindelhauer ${ }^{a, c, d}$ \\ a Medical Genetics, Childrens Hospital, Ludwig Maximilians University, b Medical Genetics Center, MGZ, and \\ c Institute of Human Genetics, Technical University, Munich; \\ ${ }^{\mathrm{d}}$ Livestock Biotechnology, Life Sciences Center Weihenstephan, TUM, Freising (Germany)
}

\begin{abstract}
Human artificial chromosomes (HACs) were generated by transfer of telomerized PAC constructs containing alpha satellite DNA of various human chromosomes. To monitor which cells took up constructs and subsequently formed stable clones under blasticidin S (BS) selection, a CMV/EGFP expression cassette was inserted into a $\mathrm{HAC}$ construct based on chromosome 5 alpha satellite DNA (142 kb). Lipofection into HT1080 cells resulted in a small proportion of cells exhibiting bright green fluorescence on day 1 . Areas containing such early green cells were marked, and plates monitored over 2 weeks. In only one out of 41 marked areas, a viable clone developed. In the remaining 40 areas, the green cells ceased division at 1-8 cells. In contrast, outside the marked areas, 16 stable clones
\end{abstract}

formed which did not exhibit green fluorescence during the first cell divisions, but all cells of each became green around day 4-6. Fluorescence in situ hybridization (FISH) analysis of isolated clonal lines demonstrated low copy HAC formation without integration. We conclude that transient expression of an EGFP marker on HAC DNA is not a suitable means for the identification of the proportion of transfected cells which are capable of forming viable clones. One explanation could be that the high copy number required to consistently detect transient EGFP expression (Schindelhauer and Laner, 2002) impairs viability and clone formation.

Copyright @ 2004 S. Karger AG, Basel
Human artificial chromosomes (HACs) represent an ideal tool to stably add genetic material to cells without integration into host chromosomes. While existing chromosomes, including small marker chromosomes, can be modified and moved between cultured cells, the de novo formation of HACs offers

\footnotetext{
Supported by Vaincre la Mucoviszidose, Forschungsgemeinschaft Mukoviszidose $\mathrm{eV}$, the Friedrich Baur Stiftung, and the Deutsche Forschungsgemeinschaft (DFG).

Received 29 April 2004; manuscript accepted 28 May 2004

Request reprints from Dr. Dirk Schindelhauer, Livestock Biotechnology Life Sciences Center Weihenstephan, Hochfeldweg 1

DE-85354 Freising (Germany)

telephone: +49816171 2028; fax: +498161712108

e-mail: dirk.schindelhauer@wzw.tum.de

Present address of T.S.: Childrens Hospital, University of Würzburg Würzburg (Germany)
}

the opportunity to assemble novel chromosomes from isolated DNA sequences. Hitherto, a variety of chromosome-specific alpha satellite DNA arrays of various human chromosomes, including chromosomes $2,5,8,11,15,19,21,22, \mathrm{X}$, and $\mathrm{Y}$ have been transferred as purified DNA in order to form centromeres of de novo HACs (Harrington et al., 1997; Ikeno et al., 1998; Henning et al., 1999; Ebersole et al., 2000; Schueler et al., 2001; Grimes et al., 2002; Mejia et al., 2002; Ohzeki et al., 2002; Kouprina et al., 2003). HACs have been obtained with circular constructs containing alpha satellite DNA as the only human sequence component (Ebersole et al., 2000), demonstrating the pivotal role of a functional centromere, or with linearized alpha satellite constructs containing telomere sequences and/or genomic copies of genes (Grimes et al., 2001; Mejia et al., 2001; Ikeno et al., 2002).

The de novo formation of HACs involves a process of chromatinization. It is known that attracting nuclear proteins in the target cells is facilitated by chromosome functional sequences

\footnotetext{
KARGER Fax +41613061234 E-mail karger@karger.ch www.karger.com

(C) 2004 S. Karger AG, Basel 0301-0171/04/1072-0009\$21.00/0
}

Accessible online at: www. karger.com/cgr 
(telomeres, centromeres). Usually, input molecules tend to form concatemers (Harrington et al., 1997; Ikeno et al., 1998; Mejia et al., 2001; Rudd et al., 2003), and the efficiency of the formation of a stable clone may depend on the load and structure of the transferred DNA, which might interfere with subsequent cell division, for example due to irreparable double strand breaks.

Using current techniques, the proportion of cells which form HACs is still rather small. To develop efficient HAC transfer, it would be helpful to know which cells on a plate actually took up the DNA constructs, and what proportion of such physically successfully transfected cells are capable of developing viable clones. This would help to distinguish between the very different barriers to the formation of a stable clone, that is the physical transfer at all, the physical transfer of a supportive copy number, and the capacity of the transferred DNA sequence to acquire genetic function.

Here we analyze whether a CMV/EGFP expression cassette present on large HAC constructs $(142 \mathrm{~kb})$ could be used to monitor lipofected HT1080 cells over the time. The specific question was whether transient expression from HAC constructs, visible under the microscope one day after lipofection, was a measure of the number of physically successfully transfected cells, and how many of these cells would form stable clones. We questioned this, because we recently found that a high copy number $\left(>10^{3}\right)$ of the CMV/EGFP expression cassette present on linear or circular plasmid DNA (pEGFP-N1, Clontech) is required to detect green fluorescence at day 1 in the majority of cells (HT1080 and other cell types), which physically obtained the DNA by intranuclear microinjection (Schindelhauer and Laner, 2002). Transfection of HAC constructs in this copy number range $\left(10^{3}\right.$ per cell $)$ would require transfer of a large amount of DNA, since the 1.7-kb-sized CMV/EGFP/ SV40-polyA expression cassette occupies only $1.2 \%$ of the HAC construct, compared to $36 \%$ of the EGFP-N1 plasmid. One thousand copies of the construct $\mathrm{TTE}_{1}$ used in this study would for example exceed the content of one replicated human chromosome 20. However, such a calculation may be misleading, as the DNA fraction physically transferred to the nucleus after lipofection is unknown. In addition, a copy numberdependent transient expression has not been observed for very high DNA loads, using lipofection of $1 \mu \mathrm{g}$ of EGFP plasmid per $1.5 \mathrm{~cm}$ well $\left(570 \mathrm{ng} / \mathrm{cm}^{2}\right)$ or a 24 -fold dilution (Walker et al., 2004).

\section{Materials and methods}

\section{Vector construction}

P1 phage based artificial chromosomes (PACs) (Ioannou et al., 1994), known to allow stable cloning of long arrays of highly homogeneous centromeric tandem repeat arrays in E. coli (Schindelhauer and Schwarz, 2002), were used for construction. HAC construct $\mathrm{TTE}_{1}(142 \mathrm{~kb})$ contains a $116-\mathrm{kb}$ $\alpha$-satellite array from chromosome 5 , belonging to the subtype of the dimeric alpha satellite family present on human chromosomes 1, 5, and 19 (Archidiacono et al., 1995). The homogeneous array in construct $\mathrm{TTE}_{1}$ contains $0.34 \mathrm{~kb}$ EcoRI higher order repeats as revealed by restriction analysis (not shown). TTE 1 was isolated from PAC library RPCI 704 (Ioannou et al., 1994) by array-specific PCR using primers 5IF (5'-GTG AGG AAA CAG TCT GTT TGT C) and 5IR (5'-GAA TCA TTC TGT CTA GTT TTT ATA C). Primer sequences were derived by sequencing the $0.7-\mathrm{kb}$ insert of plasmid
pZ5.1 (Hulsebos et al., 1995; http://www.biologia.uniba.it/rmc/5-alfoidi/ -alfoidiplasmids.html, EMBL/GenBank accession number AJ717298). The NotI insert of PAC E1 $(116 \mathrm{~kb})$ has been cloned into the Bsp120I site of pTT $(26 \mathrm{~kb})$, a tetratelomeric PAC vector, which was generated from the ditelomeric PAC vector pTAT-BS (17 kb, Ebersole et al., 2000; EMBL/GenBank accession numbers BN000528 and BN000529), by insertional duplication of the portion between the telomeres, insertion of a prokaryotic white/blue selectable marker derived from pUC19 (Gibco BRL), and insertion of an eukaryotic CMV/EGFP expression cassette $(1.7 \mathrm{~kb})$ derived from plasmid pEGFP-N1 (Clontech) by PCR with primers GGF (5'-CCT GAT TCT CGA GAT AAC CGT ATT ACC GCC ATG) and GGR (5'-GGA TAG TGG AGT CGA CTT CCA AAC TGG AAC AAC ACT C). The duplicated arrangement of vector sequences resulted in the presence of two copies of the blasticidin $\mathrm{S}$ (BS)-selectable marker, while only one copy of the EGFP cassette is present (see Fig. 1b). Function of the EGFP cassette within the sequence context of vector pTT was checked using intranuclear microinjections $\left(10^{4}-10^{5}\right.$ copies per injection volume) and transient expression analysis according to the assay previously described (Schindelhauer and Laner, 2002).

\section{PAC DNA preparation}

Pure intact TTE $_{1}$ DNA was prepared from agarose plugs as described (Schindelhauer and Cooke, 1997). E. coli DH10B (Gibco BRL) harboring PAC TTE $_{1}$ were grown overnight in $50 \mathrm{ml} \mathrm{LB}$ supplemented with ampicillin (Sigma; $100 \mu \mathrm{g} / \mathrm{ml}$ ) and kanamycin (Sigma; $30 \mu \mathrm{g} / \mathrm{ml})$. After $12 \mathrm{~h}, 200 \mathrm{ml}$ of fresh LB amp/kana was added and incubated for $2-3 \mathrm{~h}$ at $37^{\circ} \mathrm{C}$. $30 \mathrm{~min}$ before harvest, $84 \mu \mathrm{g} / \mathrm{ml}$ chloramphenicol (Sigma) was added in order to complete ongoing PAC replication without re-initiation. Cells were centrifuged (Beckman J-21B; 4,000 rpm, $15 \mathrm{~min}, 4^{\circ} \mathrm{C}$ ), resuspended in $10 \mathrm{ml}$ buffer Pett IV (10 mM Tris, $\mathrm{pH} 7.4 ; 1 \mathrm{M} \mathrm{NaCl})$ and washed by centrifugation $\left(4,000 \mathrm{rpm}, 15 \mathrm{~min}, 4^{\circ} \mathrm{C}\right)$. The pellet was resuspended $1: 1(\mathrm{v} / \mathrm{v})$ in Pett IV $\left(42^{\circ} \mathrm{C}\right)$ and the suspension mixed $1: 1(\mathrm{v} / \mathrm{v})$ with $2 \%$ low melting point agarose (Gibco BRL; "ultrapure", melted and cooled to $42^{\circ} \mathrm{C}$ ). Plugs were allowed to set on ice in disposable plug molds (Biorad), and transferred to $30 \mathrm{ml}$ EC-Lysis buffer (6 mM Tris, $\mathrm{pH} 7.4 ; 1 \mathrm{M} \mathrm{NaCl} ; 100 \mathrm{mM}$ EDTA, $\mathrm{pH}$ 7.8; $0.5 \%$ Brij 58; $0.2 \%$ deoxycholate; $0.5 \%$ N-lauroyl-sarkosin) freshly supplemented with lysozyme (Fluka BioChemika; $50 \mu \mathrm{g} / \mathrm{ml}$ ) and RNase A (Roche; $10 \mu \mathrm{g} / \mathrm{ml}$ ) and incubated for $12-24 \mathrm{~h}$ at $37^{\circ} \mathrm{C}$. To remove cell debris, plugs were incubated for 2 days in $20 \mathrm{ml}$ of buffer NDS (0.5 M EDTA, pH 9; after sterilization $1 \% \mathrm{~N}$-lauroyl-sarkosin) containing proteinase $\mathrm{K}$ (ICN; $10 \mu \mathrm{g} / \mathrm{ml}$ ) at $50^{\circ} \mathrm{C}$, and for 2 weeks at room temperature (RT) changing NDS every 2 days. Plugs were stored in NDS at RT in the dark. To remove E. coli DNA and nicked or broken PACs, the E. coli DNA was linearized using AscI (does not cut in the PAC) according to the manufacturer's instructions, and removed from the plugs by pulsed field gel electrophoresis $(1-60 \mathrm{~s}$ switch time, $6 \mathrm{~V} / \mathrm{cm}, 16 \mathrm{~h}, 0.5 \times \mathrm{TAE})$. Telomerized constructs were isolated by NotI digestion (New England Biolabs), pulsed field separation (1-30 s switch time, $6 \mathrm{~V} / \mathrm{cm}, 16 \mathrm{~h}$ ) (see Fig. 1c), and electroelution in 0.25× TAE using a BioTrap BT1000 (Biometra).

\section{Cell culture, lipofection and selection of stable cell lines}

HT1080 cells were grown in DMEM (Gibco BRL) supplemented with $10 \%$ FCS (Biochrom, Berlin, Germany) and $2 \%(\mathrm{v} / \mathrm{v})$ penicillin/streptomycin (Gibco BRL). Petri dishes $\left(75 \mathrm{~cm}^{2}\right)$ containing approximately $5 \times 10^{5}$ HT1080 cells ( $\sim 50 \%$ confluency) were washed with PBS (Gibco BRL). For each plate, $10 \mu$ l LipofectAMINE Reagent ${ }^{\mathrm{TM}}$ (Gibco BRL) and $190 \mu \mathrm{l} \mathrm{Opti-}$ MEM-I (Gibco BRL) were thoroughly mixed and incubated for $25 \mathrm{~min}$ at RT. 5 min prior to transfection, the DNA solution was prepared using approximately $150 \mathrm{ng}$ of TTE $\mathrm{T}_{1}$ DNA (in $0.25 \times$ TAE) added to OptiMEM-I resulting in a volume of $200 \mu \mathrm{l}$. The DNA was gently mixed with the lipofection mixture and incubated for $5 \mathrm{~min}$ at RT. The solution was added to the cells with $2 \mathrm{ml}$ OptiMEM-I. Plates were placed on a support leveled to obtain an equal distribution of liposome complexes $\left(\sim 2 \mathrm{ng} \mathrm{DNA} / \mathrm{cm}^{2}\right)$, and incubated at $37^{\circ} \mathrm{C}$. After $12 \mathrm{~h}$, cells were washed with medium and incubated for 1 day without selection, and for 14 days in medium supplemented with $4 \mu \mathrm{g} / \mathrm{ml}$ blasticidin S (ICN), which was changed every second day. Individual colonies were picked and subsequently expanded in 6-well dishes and T25flasks until 30 days of growth for FISH analysis.

Monitoring transient expression and stable clone formation

Transfected plates were screened every day by bright field and fluorescence microscopy using a Zeiss Axiovert 10 equipped with a HBO 50 lamp 


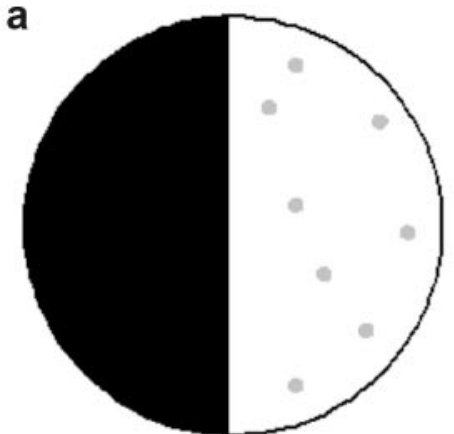

day 1

b

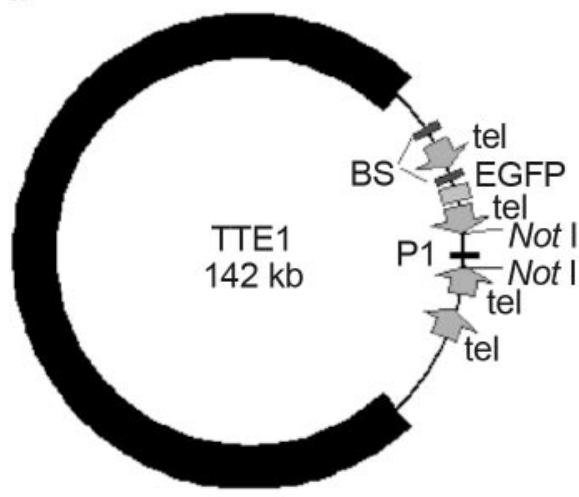

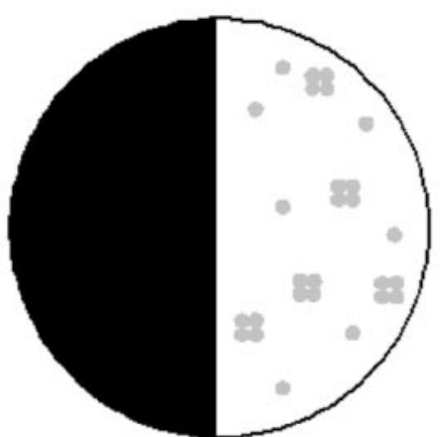

day 6

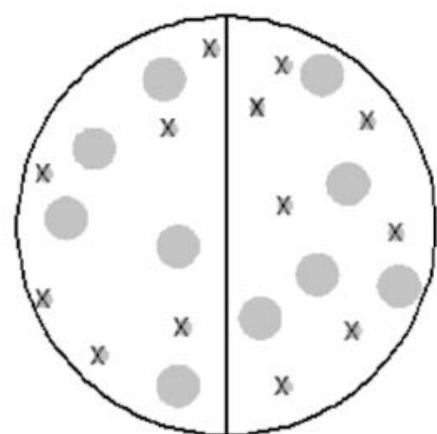

day 14

d
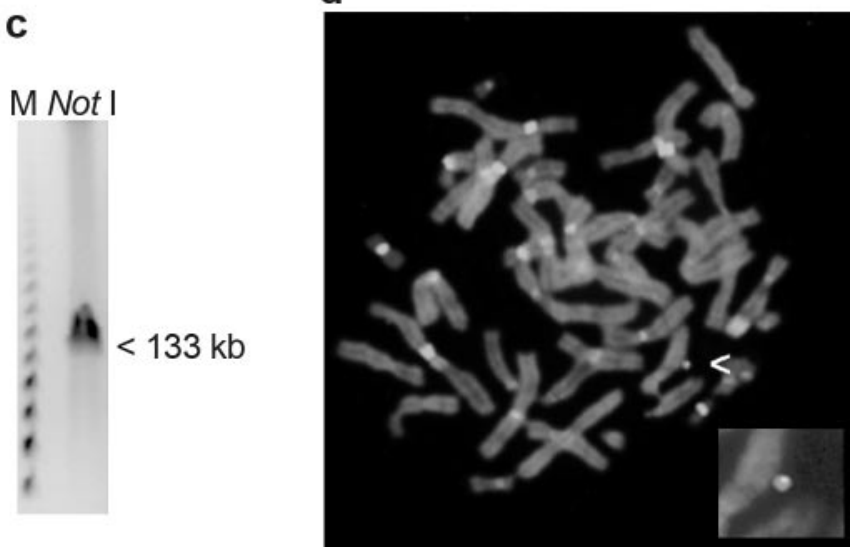

Fig. 1. Monitoring expression from an EGFP cassette present on a HAC construct. (a) Sections of $50 \%$ of eight plates $(\varnothing 10 \mathrm{~cm})$ containing approximately $5 \times 10^{5}$ HT1080 cells were taped to exclude light damage from daily bright field and fluorescence microscopy screens. Per plate, $\sim 150 \mathrm{ng}$ of Not cut, electroeluted TTE ${ }_{1}$ was lipofected, and EGFP expression and clone formation screened over a period of 14 days. At day 1, 41 "early" green cells (either singletons or doublets) were identified and areas marked $(\varnothing 5 \mathrm{~mm}$, indicated as small gray dots). At day 14, only one viable green colony had developed in such an early marked area (not illustrated). In 40 areas, the green cells ceased growth, mostly at the 1-2 or up to 8 cell stage (indicated as small gray dots with an $\mathrm{X}$ ). Outside of the marked areas, 16 viable clones developed, but EGFP expression became detectable not before a multiple cell stage (8-32) between days 4 and 6 (indicated as quadruplet gray dots at day 6). These "late" green cells grew under selection and resulted in uniformly green, viable colonies at day 14 (illustrated as large gray dots). At day 14, a similar picture was observed in the uncovered control sections. (b) Schematic

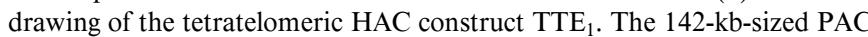
contains four arrays of (TTAGGG) $)_{135}$ (tel), a duplicated arrangement of vec- tor sequences with 2 copies of the blasticidin $\mathrm{S}$ resistance marker (BS), and a CMV/EGFP expression cassette (EGFP). A 116-kb alpha satellite array of human chromosome 5 (black bar) was cloned from a PAC (E1) by conventional cloning. The PAC backbone (P1) is removed by NotI restriction, resulting in a 133-kb-sized, telomerized HAC construct. (c) Integrity of the NotI fragment was checked on a pulsed field gel prior to lipofection (M, Midrange Marker II, NEB). Approximately the 100-fold amount of DNA was loaded on a quantitative pulsed field gel and excised without UV illumination for electroelution (not shown). (d) Two EGFP expressing (late) lines, TTE $1-12$ and $\mathrm{TTE}_{1}-14$, were picked and expanded for 30 days (approximating 30 generations). Metaphase spreads ( $\mathrm{n}>15)$ were analyzed by FISH using alpha satellite probe cen5I (from PAC E1) staining the centromeres of chromosomes 1, 5 , and 19, and vector probe Rsf including the BS selectable marker. Both probes showed colocalization on low copy, episomal DAPI elements without integration into host chromosomes, demonstrating HAC formation in both lines. Shown is a typical HAC (arrow) in a metaphase of line $\mathrm{TTE}_{1}-14$ (inset: magnification of the $\mathrm{HAC}$ ). and filter set F41-018 (HQ 470/40, 495, HQ 500 LP) in a dark room. Cells expressing at day 1 were marked by circles and plates were monitored over a period of 14 days. In order to exclude light damage by frequent illumination, the dish bottoms were taped half (Fig. 1a). At day 14, the taped sections were uncovered, and the plates were screened for individual cells and colonies using bright field and fluorescence microscopy.

\section{FISH analysis}

Cells enriched for metaphases using $0.4 \mathrm{mg} / \mathrm{ml}$ Colcemid (Roche) for $4 \mathrm{~h}$, were treated at $37^{\circ} \mathrm{C}$ for $40 \mathrm{~min}$ in $0.8 \%(\mathrm{w} / \mathrm{v})$ sodium citrate. Nuclei were fixed in methanolacetic acid $(3: 1)$ at $-20^{\circ} \mathrm{C}$ for standard chromosomal spreads. RNase A and pepsin (Roche) treated chromosome preparations were dehydrated in ethanol. Chromosomal DNA and probes were simultaneously denatured at $72{ }^{\circ} \mathrm{C}$ for $5 \mathrm{~min}$ in $50 \%(\mathrm{v} / \mathrm{v})$ formamide, $2 \times \mathrm{SSC}, 20 \%$ (w/v) dextran sulfate and incubated in a humid chamber at $37^{\circ} \mathrm{C}$ for $72 \mathrm{~h}$. FISH hybridization was carried out in the presence of $1 \mathrm{mg} / \mathrm{ml}$ salmon testes DNA (Sigma). Post-hybridization washes were carried out in $4 \times$ SSC, $0.2 \%$ $(\mathrm{v} / \mathrm{v})$ Tween- 20 and in $2 \times \mathrm{SSC}, 50 \%$ formamide at $42^{\circ} \mathrm{C}$. After blocking with $3 \%$ (w/v) BSA, Cy3.5-conjugated avidin (Rockland, Gilbertsville) or FITCconjugated anti-digoxigenin antibody (Roche) was bound in $1 \%(\mathrm{w} / \mathrm{v}) \mathrm{BSA}$, $4 \times$ SSC, $0.2 \%(\mathrm{v} / \mathrm{v})$ Tween- 20 . Slides were washed $(4 \times$ SSC, $0.2 \%$ Tween- 20 , $\left.42{ }^{\circ} \mathrm{C}\right)$ and counterstained with DAPI (4',6-diamidino-2-phenylindole; Sigma), mounted with antifade (PPD) and analyzed on a Leica DM RXA with a CCD camera controlled by Q-FISH software (Leica Microsystems). The vector probe Rsf was derived by PCR from pTAT-BS using primer Rsf (5'-AGC GGT CGG ACC GTG CTC), which amplifies a 3.15 -kb vector fragment spanning the BS selectable marker. The PCR product was labeled by incorporation of biotin-16-dUTP (Roche) in a PCR reaction. Probe cen5I was ampli- 
fied from PAC E1 using primers 5IF/R and labeled by PCR incorporation of digoxygenin-11-dUTP (Roche). Note that the signals of the vector probe are usually scaled up, while the centromere signals are kept at low intensity to minimize cross-hybridization with the alpha satellite arrays of other chromosomes.

\section{Results}

Lipofection of the telomerized artificial chromosome construct $\mathrm{TTE}_{1}$ gave rise to 41 bright green cells (1-12 per half plate, on 8 plates, from 2 experiments) $24 \mathrm{~h}$ after transfer. Areas of $\sim 5 \mathrm{~mm}$ diameter were marked around the early green cells in order to investigate cell growth over the course of time (illustrated as small gray dots in Fig. 1a). Most of the marked areas contained either single or doublet $(n=37)$ green cells at day 1 post transfection which ceased growth at this stage. A minority of the early green cells divided to 4 or 8 cells $(n=4)$ by day 6 , but finally also stopped dividing. During subsequent incubation under selection, all cells surrounding the green cells died and detached, excluding any resistant cells growing without expressing EGFP. At day 14, only one of the 41 early green areas contained a growing colony. However, outside of the marked areas, where no green cells were detected at day 1, 16 viable clones developed ( $0-7$ per half plate). These colonies were not fluorescent before day 4-6, at which time they comprised 8-32 cells (illustrated as groups of 4 gray dots in Fig. 1a). Strikingly, the cells of the viable clones became successively brighter and appeared uniformly green. All 16 clones grew until day 14. No stable clone was observed, which did not become green. At day 14, the taped areas were uncovered and also screened; 9 viable clones and 29 green cells that ceased growth at the $1-8$ cell stage were detected.

Two such green clones (TTE $\mathrm{T}_{1}-12$ and -14$)$ were picked and expanded for 30 days under BS selection (approximating 30 generations). After this period, the cell lines showed bright and uniformly green cells, indicating stable inheritance of the BSselectable marker and of the adjacent EGFP cassette, as well as stable expression from the construct. In order to distinguish between HAC formation and integration into host chromosomes, the two expanded late green lines were analyzed by dual color FISH using cen5I (green) and PAC vector (red) probes. Both probes stained low copy (probably one per cell), episomal DAPI-positive HACs in the lines $\mathrm{TTE}_{1}-12$ and $\mathrm{TTE}_{1}-14$ (Fig. 1d; white arrow), without integration into host chromosomes in all metaphases analyzed $(n>15)$. The data demonstrate the formation of stably segregating HACs in the expanded clones, which arose from areas of the plate where no early green cells could be detected.

\section{Discussion}

In order to check the usefulness of a CMV/EGFP expression cassette present on a HAC construct for monitoring physical transfer and clone formation, we lipofected the PAC construct $\mathrm{TTE}_{1}$ into the human lung sarcoma cell line HT1080. Expression was monitored by fluorescence microscopy from an early, transient stage at day 1 post transfection until formation of stable clones. Using this simple assay, we made the striking observation that the transfer events allowing early detection via transient expression, and the transfer events leading to stably expressing clones were mutually exclusive. Cells which were fluorescent at day 1 ceased growth, and cells that led to stable clones where not detectable at day 1 , but became fluorescent by day 4-6 after several cell divisions (with one exception). Since the numbers of green cells that ceased growth, and that of stable colonies, were comparable in the taped and illuminated sections (both types of transfectants were somewhat less in the dark sections, possibly due to inaccurate leveling), a negative effect of daily illumination on cell viability and clone formation was excluded. As viable clones developed strong expression at a later stage, it is also excluded that any toxicity of EGFP protein could have impaired cell division in HT1080. More likely, early transient expression was indicative for a type of transfection event not supporting viable clones, possibly due to a high DNA load.

Previous studies using direct physical transfer by intranuclear microinjection and analysis of transient expression showed that low copy numbers of the EGFP expression cassette present on a small plasmid are not suitable to detect presence of constructs in the majority of cells surviving injection. Consistently, copy numbers of $10^{3}$ per nucleus were required in various cell types including HT1080, and $10^{4}$ or $10^{5}$ copies led to brighter signals, detectable within $2 \mathrm{~h}$ post injection. However, in a small fraction of $\sim 5 \%$ of microinjected cells, exceptionally high expression occurred, which allowed the detection of as few as 10-100 copies (Schindelhauer and Laner, 2002). According to these experiments, it is obvious that the number of cells showing transient expression can be highly variable (0-100\%), even if $100 \%$ of cells physically obtained a copy number somewhere between 1 and $10^{3}$.

By analogy to the microinjection assay, one could argue that most of the early green cells from the present study might have received high copy numbers of the HAC construct, while the clone forming cells received low copy numbers. However, it could be that the 41 early green cells belonged to a much larger fraction with moderate copy numbers, out of which only a small set was detectable due to exceptionally high expression (according to 10-100 plasmid copies being detectable in 5\% of cells in a microinjection, see Schindelhauer and Laner, 2002). In this case, a large number of physically transfected cells would not be detected by transient expression. Possibly, the cells capable of forming stable clones might have derived from such a larger fraction with a moderate or low copy number.

One hint supporting clone formation from low copy numbers is the observation that microinjection of only 1-10 HAC molecules per nucleus resulted in one stable clone per 400-500 injections (unpublished data; Ikeno et al., 1998). Given that only $50-90 \%$ of injected HT1080 cells immediately survive injection (Schindelhauer and Laner, 2002), and some nuclear destruction might further reduce the rate of long term viability, clone formation per se could well exceed the level of one or a few percent. 


\section{Conclusions}

We conclude that early transient expression of a CMV/ EGFP expression marker present on a HAC is not a suitable means for detecting the fraction of transfected cells which subsequently form viable clones. In contrast, there is a striking inability of early green cells (presumably higher copy) to form stable clones, whereas cells with undetectable fluorescence before day 4-6 (presumably lower copy) can form viable clones, which turn green at a multiple-cell stage, on the base of stable inheritance of expressing HACs. Thus, cells should be moni- tored for at least 6 days (i.e. generations), if aiming at the detection of functional HAC transfer. This would help to distinguish the stable expression in viable clones from the cells with a bright mark of death.

\section{Acknowledgements}

We thank T. Hulsebos for the kind gift of the pZ5.1 plasmid and Michael Speicher for access to fluorescence microscopy and help during FISH analysis. The HT1080 cells were a kind gift of Brenda Grimes and Christine Farr. We thank Alex Kind for kind review of the manuscript.

\section{References}

Archidiacono N, Antonacci R, Marzella R, Finelli P, Lonoce A, Rocchi M: Comparative mapping of human alphoid sequences in great apes using fluorescence in situ hybridization. Genomics 25:477484 (1995).

Ebersole TA, Ross A, Clark E, McGill N, Schindelhauer D, Cooke H, Grimes B: Mammalian artificial chromosome formation from circular alphoid input DNA does not require telomere repeats. Hum Mol Genet 9:1623-1631 (2000).

Grimes BR, Schindelhauer D, McGill NI, Ross A, Ebersole T, Cooke HJ: Stable gene expression from a human artificial chromosome. EMBO Rep 21: 910-914 (2001).

Grimes BR, Rhoades AA, Willard HF: Alpha-satellite DNA and vector composition influence rates of human artificial chromosome formation. Mol Ther 5:798-805 (2002).

Harrington JJ, Van Bokkelen G, Mays RW, Gustashaw K, Willard HF: Formation of de novo centromeres and construction of first-generation human artificial microchromosomes. Nat Genet 15:345-355 (1997).

Henning KA, Novotny EA, Compton ST, Guan XY, Liu PP, Ashlock MA: Human artificial chromosomes generated by modification of a yeast artificial chromosome containing both human alpha satellite and single-copy DNA sequences. Proc Natl Acad Sci USA 96:592-597 (1999).
Hulsebos TJ, Gilbert DJ, Delattre O, Smink LJ, Dunham I, Westerveld A, Thomas G, Jenkins NA, Copeland NG: Assignment of the beta B1 crystallin gene (CRYBB1) to human chromosome 22 and mouse chromosome 5. Genomics 29:712-718 (1995).

Ikeno M, Grimes B, Okazaki T, Nakano M, Saitoh K, Hoshino H, McGill NI, Cooke H, Masumoto H: Construction of YAC-based mammalian artificial chromosomes. Nat Biotechnol 16:431-439 (1998).

Ikeno M, Inagaki H, Nagata K, Morita M, Ichinose H, Okazaki T: Generation of human artificial chromosomes expressing naturally controlled guanosine triphosphate cyclohydrolase I gene. Genes Cells 7:1021-1032 (2002).

Ioannou PA, Amemiya CT, Garnes J, Kroisel PM, Shizuya H, Chen C, Batzer MA, de Jong PJ: A new bacteriophage $\mathrm{P} 1$-derived vector for the propagation of large human DNA fragments. Nat Genet 6:84-89 (1994).

Kouprina N, Ebersole T, Koriabine M, Pak E, Rogozin IB, Katoh M, Oshimura M, Ogi K, Peredelchuk M, Solomon G, Brown W, Barrett JC, Larionov V: Cloning of human centromeres by transformationassociated recombination in yeast and generation of functional human artificial chromosomes. Nucleic Acids Res 31:922-934 (2003).

Mejia JE, Willmott A, Levy E, Earnshaw WC, Larin Z: Functional complementation of a genetic deficiency with human artificial chromosomes. Am J Hum Genet 69:315-326 (2001).

Mejia JE, Alazami A, Willmott A, Marschall P, Levy E, Earnshaw WC, Larin Z: Efficiency of de novo centromere formation in human artificial chromosomes. Genomics 79:297-304 (2002).
Ohzeki J, Nakano M, Okada T, Masumoto H: CENP-B box is required for de novo centromere chromatin assembly on human alphoid DNA. J Cell Biol 159:765-775 (2002).

Rudd MK, Mays RW, Schwartz S, Willard HF: Human artificial chromosomes with alpha satellite-based de novo centromeres show increased frequency of nondisjunction and anaphase lag. Mol Cell Biol 23:7689-7697 (2003).

Schindelhauer D, Cooke HJ: Efficient combination of large DNA in vitro: in gel site specific recombination (IGSSR) of PAC fragments containing alpha satellite DNA and the human HPRT gene locus. Nucleic Acids Res 25:2241-2243 (1997).

Schindelhauer D, Laner A: Visible transient expression of EGFP requires intranuclear injection of large copy numbers. Gene Ther 9:727-730 (2002).

Schindelhauer D, Schwarz T: Evidence for a fast, intrachromosomal conversion mechanism from mapping of nucleotide variants within a homogeneous alpha-satellite DNA array. Genome Res 12:1815-1826 (2002)

Schueler MG, Higgins AW, Rudd MK, Gustashaw K, Willard HF: Genomic and genetic definition of a functional human centromere. Science 294:109115 (2001).

Walker WE, Porteous DJ, Boyd AC: The effects of plasmid copy number and sequence context upon transfection efficiency. J Control Release 94:245252 (2004). 